\title{
Re-Thinking an Educational Model Suitable for 21st Century Needs
}

\author{
Tim Birtwistle and Robert Wagenaar
}

\section{Introduction}

One can observe a growing disconnect between the deliveries of present educational programmes and the needs of society (UNESCO 2015; (European Commission 2017); OECD 2019). This should be a concern for society at large and the higher education sector in particular. This observation, and concern, requires a scholarly underpinning, on the one hand, and defining an articulated way forward, on the other.

Already in 1997, the European Commission introduced the notion of 'knowledge society' in its Communication Towards a Europe of Knowledge (Commission of the European Communities 1997). It builds on EC papers published since the beginning of the 1990s, of which the White Paper Teaching and learning. Towards the learning society (Commission of the European Communities 1997) is of particular relevance in this context. The Communication published one year before the Sorbonne Declaration (Bologna Process 1998) and two years before the Bologna Declaration (Bologna Process 1999) combines the notions of knowledge policies and promoting employability. This is no surprise because in these years, the European economy was thought to be in a dip, as a result of regional and global incidents (World Bank 2005) but also more fundamental issues, although in the last years of the 20th century there were signs of recovery in the EU. Nevertheless, there was a good reason why the IMF devoted a full chapter, titled 'Chronic Unemployment in the Euro Area: Causes and Cures', in its World Economic Outlook of May 1999 (IMF 1999). In the EC Communication, it is observed that 'Economic competitiveness, employment and the personal fulfilment of the citizens of Europe is no longer mainly based on the production of physical goods, nor will it be in the future. Real wealth creation will henceforth be linked to the production and dissemination of knowledge and will

T. Birtwistle $(\bowtie)$

Leeds Beckett University, Leeds, UK

e-mail: tim.birtwistle@hedconsultant.co.uk

R. Wagenaar

University of Groningen, Groningen, The Netherlands

e-mail: r.wagenaar@rug.nl 
depend first and foremost on our efforts in the field of research, education and training and on our capacity to promote innovation. This is why we must fashion a veritable "Europe of knowledge". (Commission of the European Communities 1997:1)

According to the Communication, the changing context requires innovation, research, education and training policies to be reached by 'an open and dynamic European educational area' which should gradually be constructed on the basis of three dimensions: (1) development of knowledge in a Lifelong Learning context, (2) enhancement of citizenship related to mutual understanding of the cultural diversities of Europe as well on the principles of solidarity and finally (3) acquisition of the most useful set of competences required for employability taking into account the evaluation of job profiles (Commission of the European Communities 1997). It shows that both the Sorbonne and the Bologna Declarations were not original in their content, with one exception, to organise higher education in cycles (a French expression) (Wagenaar 2019a). This would allow for an appropriate differentiation of learning periods in higher education to serve society better. The White Paper on education and training expressed the concern that long-term unemployment, in particular among young people, continued to increase, resulting in social exclusion (Commission of the European Communities 1995). Having the financial crises developing one decade later, that is from 2008, this all sounds very familiar. Over the years, the European Commission kept publishing Communications which were related to the Lisbon initiative to make Europe the most competitive region of the world. We refer here to the ones published in 2003, 2005, 2006, 2011, 2017 which all gave reference to building a knowledge-based society in Europe.

During the same years, not only the challenges were highlighted, but also ideas and concepts were developed to tackle these. A discussion took off about the paradigm applied in (higher) education, until then focusing on the transfer and acquisition of knowledge pur sang-based on an expert-driven approach-instead of taking the needs of the learner and society as the point of reference. This debate coincided with one in which the notion of competence/competency was highlighted by limiting teaching not only to the field of 'learning what' but extending it to 'learning how'. In other words, the role of (higher) education should not only be to make students knowledgeable but also skilled and competent and, as a consequence, to develop the notion of learning to learn. This discourse was put into practical action more or less in parallel in the UK by the Quality Assurance Agency (QAA) which decided to develop so-called benchmark papers (ellingham 2008) and at EU level by the project Tuning Educational Structures in Europe, co-financed by the European Commission and the higher education sector (Tuning Educational Website). The relation between the two initiatives was expressed in the Transnational European Evaluation Project (TEEP) coordinated by ENQA (ENQA 2004). The European Commission asked the EU supported Thematic Network Programmes (TNPs)—perceived as an important means for cooperation and reform at the time-to follow the Tuning model. It also has to be mentioned here that in the context of the Bologna Process, a series of relevant Bologna seminars were organized. For these seminars, a selected group of academics was invited. Since 2005 the audience of these seminars was limited in particular to governmental and quality assurance organisations, creating the so- 
called 'Bologna Club' (Adelman 2008), resulting in a disconnect between levels of governance (Wagenaar 2019a). This disconnect was in 2014 described by key members of the BFUG as the 'Bologna bubble' (Bologna Process 2014).

In Tuning, the concept of generic competences and subject specific competences was introduced to relate to the needs of society (González and Wagenaar 2003). Both in the QAA and Tuning initiatives, it was proposed to change from the instruction to the learning paradigm. This philosophy was also picked up by a group of governmental officials and representatives of QA organisations from a number of European countries that called itself the Joint Quality Initiative: this group developed the 'key outcomes' commonly referred to as the Dublin Descriptors (Leegwater 2015).

It was the Tuning initiative that identified in 2001 in a meaningful way the disconnect between what should be and what was actually learned. The outcomes of a large-scale survey among relevant stakeholders showed that core generic competences were not, or were insufficiently, covered in degree programmes (González and Wagenaar 2003). Since then, many consultations with different organisations have confirmed the list of key skills and competences needed for operating successfully in society (Beneitone and Bartelomé 2004; European Commission 2010; Hart Research Associates 2013; Agència 2015). This disconnect was later rephrased (by others than Tuning) as the 'skills gap' (Moore and Morton 2017). A gap that highlighted the need for generic competences, not only (computer) literacy, but in particular critical and abstract thinking, analysing and synthesising, applying knowledge in practical situations, identify, pose and solve problems, working in teams, design and manage projects, oral and written communication, decision making, creativity and learning to learn. The problems in the financial sector have exposed the need for developing leadership skills (motivate others) and entrepreneurship. From 2009 , this was fully understood by the ministers of education when they embraced the concept of student-centred learning and the related methodology of active learning. It was the European Student Union (ESU) and Educational International, not the Bologna Follow-up Group (BFUG), that came up with a more precise definition of student-centred learning (Education International, Education International and European Student Union 2010). The BFUG found its strategy for moving towards output-based/student-centred learning in taking responsibility for the EC owned ECTS Users' Guide (Wagenaar 2019c).

Some 15 years after the signing of the Bologna Declaration, Tuning, in close cooperation with the European Commission and the Lumina Foundation for Education, took the initiative to find out whether the concept of student-centred/output-based learning was landing and being embedded in the higher education sector. The resulting study shows a clear disconnect between political ambitions and day-to-day reality. One can observe that overall reform, and the concepts involved, is not proceeding beyond the discourse involving higher education management and staff, let alone students. Academic staff, in general, are still operating on the basis of knowledge ownership, not as facilitators of a learning process. One can also observe insufficient alignment of learning, teaching and assessment and shared responsibility for the curricula on offer (Birtwistle and Wagenaar 2016). 
In the context of this paper, it seems appropriate to define better what the present and future needs of society are. It should be taken for granted that society requires real specialists as covered by the different academic domains. But it should also be highlighted that it needs high level generalists able to combine different disciplinary related knowledge and skills in a multi-disciplinary and interdisciplinary context. Real innovation results from teamwork. The recent European Commission supported project, Measuring and Comparing Achievements of Learning Outcomes in Higher Education in Europe (2016-2018), shows that currently there is slightly more attention for developing generic skills besides subject-related ones than two decades ago, but the actual application of both knowledge and these skills in practice by operating autonomously and by taking responsibility is not trained in the vast majority of degree programmes (CALOHEE Website). One instrument of developing these is work-based learning (WBL), but its (full) integration in higher education programmes is still exceptional. WBL is one approach, besides other strategies and methodologies to apply student-centred and active learning (WEXHE Website).

Regarding future societal needs, one cannot help but notice that there is a widespread dissatisfaction with the way societies and the global economy are organised. Large segments of society challenge the status quo. As a result of the globalisation of the economy and society based on a neoliberal model, many have the feeling they have lost grip on developments. This has resulted in nostalgia and the embracing of nationalism and local forms of policy making, but also challenging and blaming the 'elite', based on distrust (Kirchick 2017; Müller 2017; Wagenaar 2019a). There is an obvious need for developing civic, social and cultural engagement as part of higher education degree programmes. Applicable models are presently developed, but implementation and integration still have to come, which will be a tremendous challenge in itself (CALOHEE Project 2017). As the Council of Europe has shown, this civic awareness is highly aligned with the concept of generic competences, which brings us back to the 'skills gap' (Council of Europe 2016). The challenge for higher education (institutions) will be to educate knowledgeable and skilled graduates; this requires the balance of 'responsible citizens' able to defend and give substance to the notion of democratic society (Council of Europe 2018a,b,c) and 'successful participants in a dynamic labour market'.

These observations result in the research question of the key issues which higher education is wrestling with and, as a follow-up, what then are the elements which define a convincing response to present and future societal needs. The re-thought model should allow for empowering learners to operate as responsible citizens and be successful participants in a dynamic labour market.

\section{The Present Debate- the Contradictory Tendencies}

The present debate on higher education learning displays seemingly contradictory tendencies. On the one hand, the argument is made for graduates who are not only knowledgeable in a particular field of studies, but most of all are trained in key 
generic competences/transferable skills allowing for autonomy and responsibility, that is offer leadership and the ability to inspire others. (CALOHEE 2018). On the other hand, the argument challenges traditional learning models in favour of Lifelong Learning formats based on so-called micro-credentials/small tailored learning units (Ehlers 2018). These are expected to focus on obtaining additional (new) knowledge and the development of technical skills related to a particular domain. In this context, it is relevant to notice that 'new' knowledge and subject specific competences require a robust foundation of knowledge, skills and wider competences obtained earlier by the learner. Wider competences include values and attitudes.

The need for LLL in terms of re-entering learning, entering learning at a mature stage in life, needing to update a particular part of one's learning to meet new demands or learning for pleasure will have to be catered for in a variety of ways. The '60-year curriculum' will sit alongside a wide range of possibly fast-moving and changing credentials. These credentials will be of different sizes (Cochrane 2019) and will fit together in different ways.

Around the globe, countries are looking at how the landscape is changing and, in the main, coming up with largely similar outcomes even in very different contexts. One unsurprising outcome is to determine that many existing credentials will be "unbundled", and then the component parts may be "rebundled" to form new degrees. The small components of learning (micro) will allow for the creation of new large components of learning, often what existing Qualifications (Reference) Frameworks would recognise as a degree whilst also providing a way to satisfy the demands being made for upskilling, updating, unlearning, in new flexible patterns of access.

To create the larger components, the micro-credentials need to be "stackable" (Naughton 2018) or provide for accumulation, Naughton quotes from the United States' Department of Labor: "stackable credentials are part of a sequence of credentials accumulated over time to build up an individual's qualification to help them move along a career pathway or up a career ladder to potentially different and higher paying jobs." Stacks can then be organised to suit the world of work in three basic ways:

1. Horizontal Stacking provides breadth—e.g., Instructional Design or Facilitation Skills.

2. Vertical Stacking provides depth and level—e.g., Basic, Intermediate, or Advanced.

3. Hybrid Stacking provides both—e.g., Basic Instructional Design or Basic Facilitation Skills, Intermediate Instructional Design or Intermediate Facilitation Skills.

Stacking can also be used to suit what might be termed as more traditional degrees, for example, to sit alongside or within the national Qualifications Framework. This debate is current in Australia with the ASQA review but, for example, Deakin University apparently is concerned about this slowing down the whole venture which the university has embraced (HEA 2019). Deakin University has been working on micro-credentialing, including leading an Australian Government Office for Learning and Teaching strategic project to explore the potential of micro-credentials. Other 
examples are New Zealand's approach for micro- credentials to fit into the QF alongside major qualifications. This is similar to Ireland, Scotland, and Denmark as well as Australia.

Research shows that the labour market is in motion constantly (National Association 2018; McKinsey 2017; OECD 2018). As a result of the movement from production of goods to services, but also the rapid development of computer technology and the related growing use of artificial intelligence, jobs and professions disappear or change and are replaced by others. In this context, tasks and responsibilities of employees are changing on a regular basis. Old knowledge and skills are replaced and complemented by new knowledge and skills or develop to a higher and often more complex level of application. This implies that employees are constantly asked to upgrade their competences. Often this can be done on the basis of experience-learning by doing - but it will also require additional education and training, which has been dubbed lifelong learning. Flexibility of the workforce has become a key notion, which puts pressure on motivation and dedication. Because of (increasing) higher life expectancy, the workforce in an increasing number of countries is expected to work longer than in the past; in the near future up to a decade longer than only some years ago. This is not surprisingly challenged in a number of countries - in particular by those workers in highly demanding physical jobshowever, the argument is made that in order to be able to finance a reasonable pension, and with the changing demographics, working more years is required. This implies that after some 15-20 years of education, including higher, people will spend 40 to 45 years in the workplace. One does not have to be a prophet to foresee that with the present speed of an evolving labour market in mind, the workplace and related activities will change fundamentally during that lifespan. Although, already at the turn of the century, it was stressed by the European Commission and others that Lifelong Learning would be the new learning mode (European Commission 2001), after two decades, not very many countries (and institutions) have full lifelong learning strategies, policies and modes of implementation in place covering the full scale of fields and topics covered in higher education.

Having said this, it seems reasonable to start answering the question what is actually learned, taught and assessed in present day formal education. When responding to this question, one has to stipulate that the picture is diverse. Over time, very inspirational initiatives have been taken by both individual higher education providers and by groups of universities, often organised as EU supported projects. However, in general, it seems the change promoted in the context of the Bologna Process, as well as the Lisbon Strategy (European Commission 2010), since the start of this century, has been uneven, but most of all with not very much progress actually made (EC 2018). In a Tuning study (Birtwistle and Wagenaar 2016), funded by the European Commission, it was concluded in 2016 on the basis of structured interviews with management, (academic) staff and students that the student-centred and active learning approach was not landing in the vast majority of institutions and departments. Many interviewed, in particular younger staff and students, proved unable to recall the Bologna Process and its main objectives. Higher education management complained that they lacked the resources to initiate reforms of programmes and in 
conjunction to modernise the methods and approaches applied for learning, teaching and assessment. A consultation organised in the setting of the CALOHEE project, followed by intense discussion, confirmed this picture (CALOHEE Website).

The Qualifications Reference Frameworks developed by CALOHEE, which are based on a merger of the Qualifications Framework for the EHEA (Bologna Process 2005) and the EQF for LLL (European Commission 2008) and as a result fully aligned with these, is the most current initiative to define what to expect from a learner now and in the (near) future. The frameworks are subject area based and are therefore - compared to overarching European and national frameworks-much more explicit, offering precision. In practice, they set standards of what a programme should reflect to be relevant for the learner and society at large. They are the products of work done by informed international groups of academics. The model allows for identifying three levels of achievement for both bachelor and master. They clearly put the learner at the centre of an aligned learning, teaching and assessment process. Its real contribution is that its descriptors offer clear indicators of what is needed in the workplace and in society while respecting the requirements of the academic fields involved (Wagenaar 2018, 2019a).

Tuning CALOHEE frameworks emphasis autonomy and responsibility as the highest level of learning. This involves also practicing civic, social and cultural engagement in every programme, making a distinction between four-in the near future five-dimensions of learning: society and culture-interculturalism, processes of information and communication, processes of governance and decision making (including democratic competences) and ethics, norms, values and professional standards and in addition sustainable development (climate change). These dimensions are expected to be integrated in every degree programme in the (near) future. Dimensions are formulated as constructive key elements which define a subject area. All frameworks contain also a lifelong learning component, identified as one of its dimensions. It reflects the 4ever learning model (see Sect.3), the need to keep one-self informed, up-to-date and to act pro-actively in terms of future needs.

Lifelong learning seems to be the foundation of the development of distance learning but needs to be easily accessible and affordable. In 2006, the format of Massive Open Online Courses (MOOCs) was introduced as a follow-up of more traditional online provisions, which developed into a popular mode of learning around 2012, attracting many millions of 'learners' globally (Papano 2012). Looking back, one can speak of a temporary hype, although the format is still popular and influential. It was predicted that MOOCs would have a serious impact on formal education, maybe even replacing it (Kalman 2014; Al-Imarah and Shields 2019).

An obvious strength of MOOCs is that (the) high(est) level of knowledge has become accessible to every learner. This is at the same time its weakness. Simple transfer and acquisition of knowledge-which also includes the concept of TED talks - might make people knowledgeable, it does not make them skilled. This makes it a conservative learning model, related to frontal and expert-driven teaching. It is widely accepted now that deep knowledge can only be developed in an active learning context by a step-by-step approach of collecting knowledge, judging knowledge, analysing and synthesising knowledge and presenting new insights. This is condi- 
tional for developing real understanding of a particular issue or topic. This is not what a MOOC achieves, although one has to acknowledge that it is a very useful additional and supportive means of learning, in terms of flipped class room and blended learning models. ${ }^{1}$ During recent years, technical solutions have been found for assessing the knowledge obtained in the framework of online-learning, reaching from full degrees to digital badges, certifications of technical knowledge and skills, nanodegrees and MicroMasters. The development has led to the introduction of the term 'micro-credentials' as was mentioned earlier (Gallagher 2019).

However, these new models of learning have not significantly helped to fill the 'skills gap' identified. They are simply not tailored to demonstrating advanced skills development, which is a crucial factor for job qualification. The labour market welcomes the intertwining of (structured) education and experience, which has led to the development of work-based learning concepts as part of a formal programme. Given the type of skills which are perceived as important-such as communication, teamwork, project work, leadership, entrepreneurship_-presupposes a social environment or setting, ideally a community of learners. When organised well, formal learning should also limit drop-out.

Although the concept of micro-credentials fits very well in a rapidly changing workplace, labour market and society, and is a logical response to the need for lifelong learning, it seems that it can only partly replace class room models of learning. Nevertheless, as a result of the commercialisation of learning models, the high costs of formal higher education programmes and the promotion of competition resulting from the neo-liberal model, the traditional higher education institution is challenged. For the moment, this seems more to be the case in the United States than in Europe, where higher education is still being perceived as a public good (Bologna Process 2001, 2003; Weber and Bergan 2005) and the drop-out rates are lower (Hennen 2016; Kirp 2019). This does not mean that higher education institutions in Europe should find a response soon. An answer which should also consider its responsibility for educating students for civic, social and cultural engagement as was already stipulated.

By combining the main task of higher education institutions as education providers to prepare graduates well with the notion of a labour market which is changing with high speed, it seems reasonable to expect that higher education in the near future should tailor for lifelong learning which not only will require natural flexibility of provisions, but also allow for accessibility to it, and where needed, stacking credentials/qualifications.

\footnotetext{
${ }^{1}$ Blended learning is defined as an approach to education that combines traditional place-based classroom methods with online educational materials and interaction. In a flipped classroom, students watch online lectures, collaborate in online discussions, and/or carry out research at home while engaging in concepts in the classroom with the guidance of a mentor.
} 


\section{The Future Needs of Society}

Wherever one looks to try and determine what the role of higher education is in the first quarter of the 21 st century, a similar refrain seems to be prevalent-so many things are changing, changing fast in so many ways, so, how does higher education figure this out and have a strategy not just to cope but to lead? Titles of articles, policy papers, research papers, blogs show how the thinking is developing across the globe for example: Rethinking the Modern University (Ford 2019); Universities in 2018: Riding trends to drive change (Van Rooijen 2018); Looking to 2040: Anticipating the Future of Higher Education (DeMillo 2019); Statement of the Fifth Bologna Policy Forum (Bologna Process 2018b). However, care must be taken to analyse discretely the various interlinking strands whilst at the same time ensuring, and overtly recognising, the inevitable impact that one has upon the others. Intentionality is needed within the maze of policy and stakeholder aims. How do the interwoven and yet potentially disparate strands of governance, funding, content, access, delivery, outcomes of learning, employability, research, social responsibilities impact upon each other, and how can unintended consequences be avoided?

How are some of these changes quantified? How are the projections shown? Once again, the sources are varied with the spectrum ranging across think tanks, trade unions, higher education researchers, consultancy firms, student groups. A common approach is to anticipate (often through the analysis of data and the projections of that going forward using past directions of travel) the changes in higher education, the anticipation of future skill requirements and the skills gap perceived by employers. Liu (2019) analysed these and affirmed the view of many that higher education must engage with change in terms of learning, skills, competences, assessment, civic responsibilities, technology, artificial intelligence (AI), qualifications and credentials, access, equity, lifelong learning, recognition of prior learning and the place of knowledge sitting alongside all other things.

The National Association of Colleges and Employers 2018 Job Outlook Survey in the United States asked employers what competency was considered essential, and how proficient those entering the workforce after higher education were. The gap between proficiency and how essential that was deemed to be in all but digital technology was at times considerable, that is more than $40 \%$, for example, professionalism and work ethic, oral and written communications, critical thinking, teamwork and collaboration. These gaps are also highlighted by Van Damme (2018): "Mismatches are an important issue, as well as de-skilling as a consequence of low skills use".

The pattern of employability is also changing. McKinsey (2017) assesses the number and types of jobs that might be lost and also created under different scenarios through to 2030. The results reveal the potential shifts in occupations in the years ahead. If these come to fruition, the impact on the workforce in terms of skills (and how they are achieved) and wages will be significant. There may be full employment through to 2030, but what will the employment be? There will be different scenarios across the globe because of the current state of economies, society, and work patterns. There will be a shift in the skills required to be in work with, as one might expect, 
an ever decreasing reliance on a person holding raw data in their brain (look at your phone and analyse the computing power in your pocket) but an increasing demand for applying expertise, interacting with stakeholders and managing people. There will be changes in the level of educational attainment required to access the jobs that demand such skills.

The workplace is changing and at the forefront of the changes are digitalization and Artificial Intelligence (AI). These do impact upon higher education, not just in terms of what society will demand from it but also in terms of how it provides what it is offering. Van Damme (op. cit.) posits the notion that the value and lifespan of qualifications will be undermined by these two drivers but that learning and skills development, lifelong learning, recognition of learning will be much more relevant. Wagenaar (2019a) too recognises these changes and in similar vein to the McKinsey report identifies where the skill sets will lie and thus what the enduring learner must achieve and refresh, in his case ten key competences: critical thinking, teamwork, leadership, communication, complex problem solving, ethical judgement and decision making (reflective judgements, instead of determined-rule-basedjudgements), innovation and creativity (in the framework of learning community). Thus, the absolute need to complete the move to being able to analyse, use, seek out and create additional sources of data, information, and facts surfaces yet again with the stress always on the types of competences listed by Wagenaar (idem.).

How will the learner access the learning that they need and want? How will the provider of learning meet up with the demands of the learner? Presumably, the demands are being made because the learner believes that the employer (or purchaser of skills) is "hiring". What must change is labelling learning by a simple tag such as "distance learning" or an offering as "part-time study". The "4ever" (Birtwistle and McKiernan 2010) notion becomes stronger: [learning] "whatever, wherever, whenever, however'-it is the fact of learning and acquiring skills that is important not the method of acquiring those things. The importance of future proofing skills and use of diverse learning whilst building transversal skills is an increasingly accepted mantra (Palmén 2019) including how to learn and how to unlearn to be able to cope with change and best gain from lifelong learning (Østergaard and Nordlund 2019). The "Three Voices" shown by Palmén are representatives of students (ESU), an employer, and a creative entrepreneur. This recognition of the interwoven nature of what and how learning is to evolve and best meet the wider needs of society is essential.

In terms of what is to be the content of learning, the approach taken by CALOHEE (supra Sect. 2) provides what is possibly the most innovative, measurable, diagnostic and all-encompassing set of frameworks.

Surveying the learning landscape, Herodotou et al. (2019) provide what they state is: "a set of innovative pedagogical approaches that have the potential to guide teaching and transform learning. An integrated framework has been developed to select pedagogies .... consisting of the following five dimensions: (a) relevance to effective educational theories, (b) research evidence about the effectiveness of the proposed pedagogies, (c) relation to the development of twenty-first century skills, (d) innovative aspects of pedagogy, and (e) level of adoption in educational practice. The 
selected pedagogies, namely formative analytics, teachback, place-based learning, learning with drones, learning with robots, and citizen inquiry are either attached to specific technological developments, or they have emerged due to an advanced understanding of the science of learning. Each one is presented in terms of the five dimensions of the framework."

CALOHEE certainly includes the opportunity for continual pedagogical, learning outcomes, and learning assessment methodologies within the frameworks established and includes the changing contexts that learners are confronted with not just in terms of, for example, Artificial Intelligence, but also in terms of climate change (Extinction Rebellion 2019), civic responsibility, and being able to deal with misleading and untrue statements. This sits perfectly alongside the need to acquire the skills to deal with complex challenges and the development of the person as a whole (OECD 2018).

How the providers of learning might change is a moot point. One suspects that the current elite campus-based magnetic hubs around the world will continue largely unchanged - the elite educating their offspring in ways that mirror their own experiences and provide the total learning, social, sporting environment. For the remaining $90 \%+$, the offering will be on a spectrum of types of institutions (some remaining similar to current universities, others not so) and types of interactive streaming of learning covering skills and competences needed to quickly adapt to changing demands. Some employment will still require certification, much as now, to build the professional career ladder (medicine, law, actuarial work, etc.), however, it is likely that the vast majority may well need different types of mini-diplomas, portfolios of competences, quick tests of competence etc.

\section{A Revised Model}

As stipulated, it is expected there can be and will be a wide range of responses to the future needs of society in terms of appropriate learning models. This will be no different for higher education institutions to assure their continuous relevance as key providers of formal learning.

What seems not really debatable is that a revised higher education model—also taking into account cultural and local/regional/national differences-will demand a highly flexible format to cater for individualized learning pathways, which is expected to be based on roughly three key components:

(1) a particular field of studies (thematic or disciplinary), which can be named 'the core';

(2) a fully integrated set of key transferable skills/generic competences and

(3) additional units to the core-which can be organised as minors, electives, windows for work-based learning, international mobility, etc.

This does not sound very revolutionary, but for many higher education institutions and programmes, it will be perceived as such. What we have seen over time is that 
programmes have become more flexible, but not to the extent required by society. It is stating the obvious that 21 st Century state-of-the-art higher education programmes need to be organised with the concept of lifelong learning and the continuous need for reskilling and additional skilling in mind. In the model suggested here, it should accommodate both new and experienced learners, that is those who are already active in the workplace. Based on the discussions in and outcomes of the CALOHEE initiative, it is crucial to take as point of departure that students are prepared well for their future role. This is not the actual situation given the identified skills gap mentioned.

Research shows us that graduates with higher levels of education, e.g. higher education — short or long(er)—will stand a better chance of finding employment at a satisfying level. Formal education cannot be replaced by online micro-credentials and the like, due to the skills factor. This notion implies that every undergraduate and graduate programme is based on the development of a domain of knowledge. Development implies becoming knowledgeable, but also skilled and ultimately become inspirational to others. It requires programmes which fully intertwine knowledge and subject-specific and generic skills and competences in the learning process. A strong foundation of well understood knowledge and skills is conditional for absorbing new knowledge and additional skilling.

To accommodate for the most effective learning environment, it is important to create a stimulating and dynamic learning environment. This can be established, for example, by setting up learning communities which allow for intensive contacts between learners and academic staff. These communities are crucial components for applying modes of learning which allow for the development of - as an example - the following skills string reflecting progression of learning: teamwork, project design and implementation, leadership, entrepreneurship. While for knowledge acquisition, blended and flipped classroom learning might be helpful, learning communities will facilitate inclusive learning and social cohesion. It is in the interest of society, both in economic and social terms, to guarantee access to formal learning to all potential learners; without a sound basis, additional learning-in terms of upgrading and updating — will be frustrated.

This can be illustrated by the example of academic staff operating presently in higher education. As has been highlighted-also in the recent Paris Communiqué of the EHEA (Bologna Process 2018a) - there is a need for further engagement with the process of learning across the higher education landscape. The vast majority of higher education academic staff are subject experts with little or no pedagogical training; it might be said that they function as pilots with the experience of a passenger not knowledgeable about basic pedagogical concepts and not educated in the wide range of learning, teaching and assessment methods and approaches. As a result, the relatively new paradigm of student-centred and active learning is not taken on board, because the existing model of expert- driven education is not even understood in the consequences it has for the learner. It has been observed that facilities for staff development are not in place at the required level in most institution due to lack of trainers (Birtwistle and Wagenaar 2016 idem). 
Having said this, there is another component of learning which requires attention and covering in formal learning: the relevance of what is learned and how it is learned to be successful in and for society as a graduate. Core domain/subject-related knowledge and skills are key which should keep taking on board current achievements in the academic field, but this is not sufficient. To reach the level of application of what has been learned, a sustainable bridge between academia, the workplace and society at large has to be created and nurtured. In present day more developed models_-in particular in applied programmes - employers (and employees) play a role with respect to the design, implementation and enhancement but this role is mostly limited to offering advice as members of advisory boards and/or as guest lecturers. Only in a limited number of cases, programmes have integrated workbased learning components. Preparing for civic, social and cultural engagement is very limited or non-existent. As a result, students might become acquainted with the (most) current theoretical insights in their field of studies, but much less so with regard to practical implications and applications.

This issue can be tackled by reserving (substantial) space in both the bachelor and master programme to diversify and to broaden the scope of learning. This can be done by integrating in this space small units of specific learning, which can be perceived as micro-credentials. These micro-credentials - to be offered in this space in addition and besides mobility and work-based learning-will allow for personal profiling and, therefore, tailoring of learning for fulltime students. However, the real innovation proposed here is to make these micro-credentials also available for experienced learners in a lifelong learning context who are already active in the labour market. By bringing full-time learners and lifelong learners together to study well defined current topics, a very dynamic learning environment is created. It will combine the eagerness of learning of young people with the experience of the workplace. Such a model is cost-effective, allowing for a wide offer of state-of-the-art course units because not only high level personnel are in place but also the physical infrastructure in terms of buildings, equipment and ICT. By combining online learning with a social environment for reflection and debate, deeper learning can be achieved, which is immediately applicable in society. One can imagine a model in which alumni are informed every semester about the micro-credentials on offer of their alma mater and/or other institutions (Wagenaar 2019b).

The model described is visualised in this image (Fig. 1):

By offering small-unit learning of quality-assured education in a structured way, higher education institutions will strengthen their societal role and relevance and, therefore, also find convincing answers to decreasing student numbers in their fulltime programmes. The micro-credentials not only defined as learning units but also as communities will allow for offering (integrated) learning regarding civic, social and cultural issues as was already outlined. It will also allow-as in the case of core studies - for formative assessment besides summative assessment and for a high variation of aligned active learning, teaching and assessment strategies and approaches. The micro-credentials will be ECTS based involving both student workload and intended learning outcomes. In terms of student workload, one can imagine a variation of 2.5/5/7.5/ 10 or 3/6/9 ECTS credits. These credit arrangements will allow for 


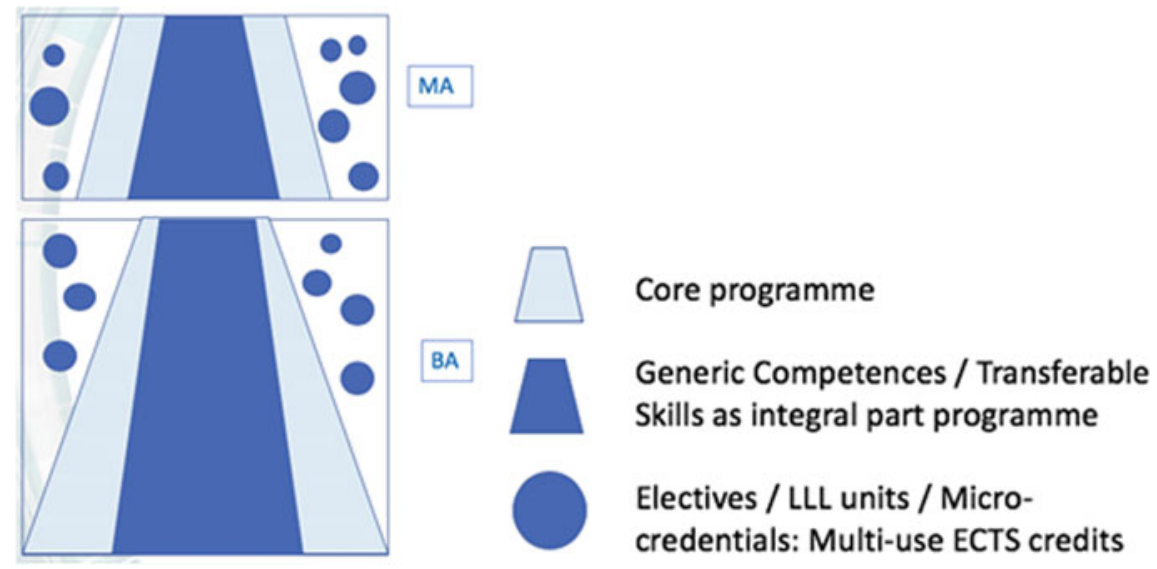

Fig. 1 Described model

accumulation or stacking. While ECTS is most of all an effective instrument to organise studies (in terms of workload and level of learning outcomes), micro-credentials as a term is applicable to express a typical mode of learning, so-called 'pockets of learning'. Of course, it is the remit of the exam boards of individual degree programmes to decide whether-in whatever combination-micro-credentials meet the standards and requirements of a first (bachelor) or second cycle (master) programme. However, these boards will no doubt be much more flexible than at present is the case, recognising the shift in the types of learning packages available.

By applying the CALOHEE Qualifications Reference Frameworks and CALOHEE Assessment Reference Frameworks, these boards will be helped to clearly distinguish and indicate levels of learning and to monitor the quality of learning which can, therefore, be guaranteed.

\section{In Conclusion}

The world is in a state of flux. Tackling the multiple problems which are complex in nature must surely rely on education at all levels. Higher education must be a central player in this immense task. As outlined, the world of work is changing, how society is reacting to change is now at a high stress level, the physical environment that we all rely on is under great stress and may be reaching a tipping point (hopefully it has not gone beyond the point of redemption), and higher education must lead by adapting its role, purposes, governance, access policies, whilst maintaining the core research function. Access to learning, re-learning (sometimes following unlearning), learning alignment, core competences, knowledge analysis, and the outcomes of learning must, as has been illustrated, be at the heart of the challenge. 
Without change, the challenges cannot be met, and the stakeholders will not begin to reach better levels of participation and satisfaction. It is said, "there is no Planet B" regarding the urgency of the environmental aspect. The employment and education surveys show change is rapid, AI is advancing faster than most are able to keep pace with (e.g. driverless vehicles, computers programming computers), the demands placed on society are great and rapid, therefore, flexible learning patterns, methods, and content based around core competences (supra) are needed now. The future is here. Higher education must adapt.

\section{References}

Adelman, C. (2008). The Bologna Club: What U.S. Higher Education Can Learn from a Decade of European Reconstruction. Washington DC: Institute for Higher Education Policy.

Agència per a la Qualitat del Sistema Universitari de Catalunya (AQA) (2015). Employers' Perceptions of the employability and skills of recent graduates in Catalonia. Main findings of the AQU Catalunya Employers Survey 2014. Barcelona.

Al-Imarah, A.A. \& Shields, R. (2019). MOOCs, disruptive innovation and the future of higher education: A conceptual analysis, Innovations in Education and Teaching International, 56(3), 258-269, DOI: https://doi.org/10.1080/14703297.2018.1443828.

Bellingham, L. (2008). Quality Assurance and the Use of Subject Level Reference Points in the UK. Quality in Higher Education, 14(3), 265-276.

Beneitone, P. \& Bartelomé, E. (2014). Global generic competences with local ownership: comparative study from the perspective of graduates in four world regions. Tuning Journal for Higher Education (THE). Competence-based learning: a global perspective. 1(2), 43-74.

Birtwistle, T. \& McKiernan, H. (2010). Making the Implicit Explicit. The Journal of College and University Law. USA: Notre Dame.

Birtwistle, T. \& Wagenaar, R. (2016). A Long Way To Go ... A Study on the implementation of the learning-outcomes based approach in the EU and the USA. Groningen.

Birtwistle, T., Brown, C. \& Wagenaar, R. (2016). A Long Way To Go ... A Study on the implementation of the learning-outcomes based approach in the EU and the USA. Tuning Journal for Higher Education, 3(2) May 2016, 429-463.

Bologna Process (1998). Joint declaration on harmonisation of the architecture of the European higher education system by the four Ministers in charge for France, Germany, Italy and the United Kingdom. Paris, the Sorbonne, 25 May 1998.

Bologna Process (1999). European Ministers for Higher Education, Joint declaration of the European Ministers of Education. Bologna 19 June 1999. Retrieved from: http://www.ehea.info/ cid100210/ministerial-conference-bologna-1999.html.

Bologna Process (2001). Towards the European Higher Education Area: Communiqué of the meeting of European Ministers in charge of Higher Education in Prague on May 19th 2001. Retrieved 10 November 2019 from: http://www.ehea.info/cid100256/ministerial-conference-prague-2001. html.

Bologna Process (2003). Realising the European Higher Education Area: Communiqué of the Conference of Ministers Responsible for Higher Education in Berlin on 19 September 2003 Berlin Communiqué . Berlin: Bologna-Berlin2003 Project Team, 2003. Retrieved 1 November 2019 from: http://www.ehea.info/cid100938/ministerial-conference-berlin-2003.html.

Bologna Process (2014). The Bologna Process Revisited: The future of the European Higher Education Area. Doc. Code: BFUG_LV_IS_43_4. Last modified 10.12.2014. Tuning Archive.

Bologna Process (2018a). Paris Communiqué 24-25 May 2018.

Bologna Process (2018b). Statement of the Fifth Bologna Policy Forum Paris May 25. 
Bologna Process (2005). A Framework for Qualifications of the European Higher Education Area. Copenhagen: Ministry of Science, Technology and Innovation, February 2005.

CALOHEE Project (2017). CALOHEE working paper for Civic, Social and Cultural Engagement. Retrieved from: https://www.calohee.eu/wp-content/uploads/2018/11/Working-Paperfor-Civic-Social-and-Cultural-Engagement-v2.pdf.

CALOHEE Website https://www.calohee.eu - accessed 1 November 2019.

Cochrane, A. (2019). Micro-credentials in 2019: The Ultimate Guide for Educators https://www. candlefox.com/blog/micro-credentials-in-2019-5-things-you-need-to-know-now/. - accessed 11 December 2019.

Commission of the European Communities (CEC) (1995). Teaching and learning. Towards the learning society. White paper on Education and Training (Luxembourg, Office for Official Publications of the European Communities).

Commission of the European Communities (CEC) (1997). Towards a Europe of Knowledge. COM(97) 563/final, Communication to the Council, the European Parliament, the Economic and Social Committee and the Committee of the Regions, Office for Official Publications of the European Communities, Luxembourg, 11 November 1997.

Council of Europe (2016). Competences for Democratic Culture: Living together as equals in culturally diverse democratic societies. Strasbourg: https://rm.coe.int/CoERMPublicCommonSearchServices/DisplayDCTMContent? documentId=09000016806ccc07.

Council of Europe (2018a). Reference Framework of Competences for Democratic Culture. Volume 1 Context, concepts and model. Strasbourg, April 2018.

Council of Europe (2018b). Reference Framework of Competences for Democratic Culture. Volume 2. Descriptors of competences for democratic culture. Strasbourg, April 2018.

Council of Europe (2018c). Reference Framework of Competences for Democratic Culture. Volume 3: Guidance for implementation. Strasbourg, April 2018.

Naughton, J. (2018). Credentialingexcellence https://www.credentialingexcellence.org/blog/5things-you-should-know-about-stackable-credentials, SPHR, MA - accessed 11 December 2019.

DeMillo, R. (2019). Looking to 20140: Anticipating the Future of Higher Education The ecoLLLution.com. 6 October 2019

Education International and European Student Union (2010). Time for a new paradigm in education: student-centred-learning. Learning SCL toolkit, Brussels. Retrieved 2 November 2019 from: http://www.aic.lv/bolona/2010/Reports/SCL_toolkit_ESU_EI.pdf.

Ehlers, U.-D. (2018). Higher Creduation - Degree or Education? The Rise of Micro-Credentials and its Consequences for the University of the Future. EDEN 2018 Annual Conference, Genua: https://www.researchgate.net/publication/327551448_higher_creduation-degree_or_ education_the_rise_of_micro-credentials_and_its_consequences_for_the_university_of_the_ future - accessed 14 December 2019.

ENQA - European Network for Quality Assurance in Higher Education (2004). Transnational European Evaluation Project. Methodological Reflections. ENQA Occasional Papers 6. Helsinki, Retrieved 30 October 2019 from: http://www.enqa.eu/indirme/papers-and-reports/occasionalpapers/TEEPmethod(1).pdf.

European Commission (2017). Communication from the Commission to the European Parliament, the Council, the European Economic and Social Committee and the Committee of the Regions on a renewed EU agenda for higher education $\{\operatorname{SWD}(2017) 164$ final $\}$ Brussels, 30.5.2017 COM(2017) 247 final.

European Commission (2010). Employers' perception of graduate employability. Analytical Report. Flash Eurobarometer 304. Survey conducted by The Gallup Organization, Hungary upon the request of Directorate-General for Education and Culture. Brussels, November 2010.

European Commission (2001). Making a European Area of Lifelong Learning a Reality. Communication from the Commission. COM (2001) 678 final. Brussels, 21 November 2001.

European Commission (2008). Recommendation of the European Parliament and of the Council of 23 April 2008 on the establishment of the European Qualifications Framework for lifelong 
learning (2008/C 111/01). in: Official Journal of the European Union 6 May 2008. Retrieved on 10 July 2018 from: https://eur-lex.europa.eu/legal-content/EN/TXT/PDF/?uri=CELEX: 32008H0506(01)\&from=EN.

European Commission/EACEA/Eurydice (2018). The European Higher Education Area in 2018: Bologna Process Implementation Report. Luxembourg: Publications Office of the European Union.

European Parliament (2010). Directorate General for Internal Policies. Policy Department A: Economic and scientific Policy. Employment and Social Affairs, The Lisbon Strategy 2000 - 2010. An analysis and evaluation of the methods used and results achieved. FINAL REPORT: http://www.europarl.europa.eu/document/activities/cont/201107/ 20110718ATT24270/20110718ATT24270EN.pdf.

Extinction Rebellion (2019) https://rebellion.earth - accessed 8 November 2019.

Ford, M. (2019). Rethinking the Modern University Resilience.org 28 August 2019.

Gallagher, S. (2019). A new era of microcredentials and experiential learning, in University World News, 15 February 2019. Retrieved on 4 November 2019 from: https://www. universityworldnews.com/post.php?story=20190213103113978.

González, J. \& Wagenaar, R. (Eds.) (2003). Tuning Educational Structures in Europe. Final Report. Phase One. Deusto and Groningen.

Hart Research Associates (2013). It Takes More than a Major: Employer Priorities for College Learning and Student Success. Washington, DC: Association of American Colleges and Universities, April 2013.

HEA https://www.heacademy.ac.uk/blog/micro-credentials-within-degrees-deakin-university Professor Beverley Oliver, Deputy Vice-Chancellor Education, Deakin University accessed 11 December 2019.

Hennen, A. (2016). America Losing? Graduation rates higher in Europe than US. Washington Examiner. 7 January 2016.

Herodotou, C., Sharples, M., Gaved, M., Kukulska-Hulme, A., Rieters, B., Scanlon, E., \& Whitelock, D. (2019). Innovative Pedagogies of the Future: An Evidence-Based Selection. Front.Educ., 11 October 2019 https://doi.org/10.3389/feduc.2019.00113 accessed 8 November 2019 page 1.

IMF (1999). Chapter IV Chronic Unemployment in the Euro Area: Causes and Cures. in: WORLD ECONOMIC OUTLOOK May 1999. A Survey by the Staff of the International Monetary Fund, pp. 88-121.

Kalman, Y.M. (2014). A race to the bottom: MOOCs and higher education business models.Open Learning: The Journal of Open, Distance and e-Learning, 29(1), 5-14, https://doi.org/10.1080/ 02680513.2014.922410.

Kirchick, J, (2017). The End of Europe. Dictators, Demagogues, and the Coming Dark Age. New Haven and New York: Yale University Press.

Kirp, D. (2019). The College Dropout Scandal. Oxford: Oxford University Press.

Leegwater, M. (2015). Joint Quality Initiative - the origin of the Dublin Descriptors - short history. The Hague. Retrieved on 8 July 2018 from: http://ecahe.eu/assets/uploads/2016/01/ Joint-Quality-Initiative-the-origin-of-the-Dublin-descriptors-short-history.pdf - also accessed 26 November 2019.

Liu, L. (2019). Assessing Core Student Learning Outcomes in Higher Education: The Current State and Global Trends. European Association for International Education, Helsinki September 2019.

McKinsey \& Company (2017). McKinsey Global Institute: Jobs Lost, Jobs Gained: Workforce Transitions in a Time of Automation.

Moore, T. \& Morton, J. (2017). The myth of job readiness? Written communication, employability, and the 'skills gap' in higher education. Studies in Higher Education, 43(3), 591-609. https:// doi.org/10.1080/03075079.2015.1067602.

Müller, J-W. (2017). What is Populism? London: Penguin Books.

OECD (2018). The Future of Education and Skills Education 2030, Paris OECD Publishing.

OECD (2019). OECD Skills Strategy 2019. Skills to Shape a Better Future. Paris, May 22, 2019. 
Østergaard, S. \& Nordlund, A. (2019). The 4 biggest challenges to our higher education model - and what to do about them, retrieved on 20 January 2020 from: https://www.weforum.org/agenda/ 2019/12/fourth-industrial-revolution-higher-education-challenges, available as part of the World Economic Forum papers January 2020.

Palmén, M. (Ed.). (2019) Three Voices: How to Future-Proof our Skills, Epale 1 November 2019: https://epale.ec.europa.eu/en/blog/three-voices-how-future-proof-our-skills-accessed 2 November 2019.

Papano, L. (2012). Year of the MOOC. in: The New York Times, November 2, 2012 https://www. nytimes.com/2012/11/04/education/edlife/massive-open-online-courses-are-multiplying-at-arapid-pace.html?pagewanted=all\&_r=0-accessed 1 November 2019.

Quality Assurance Agency for Higher Education (QAA). Subject Benchmark Statements. Statements Setting out What Achievement Is Expected According to Level and Subject. Retrieved 10 November 2019 from: http://www.qaa.ac.uk/AssuringStandardsAndQuality/subject-guidance/ Pages/Subject-benchmark-statements.aspx.

The National Association of Colleges and Employers 2018 Job Outlook Survey in the United States https://www.naceweb.org - accessed 5 November 2019.

Tuning Educational Structures in Europe Website: https://www.unideusto.org/tuningeu/ - accessed 11 November 2019

UNESCO (2015). Rethinking Education Towards a global common good? Paris: United Nations Educational, Scientific and Cultural Organization.

Van Damme, D. (2018). The Changing Higher Education Landscape and the Role of Quality Assurance. EQAF November 2018, slide 35.

Van Rooijen, M. (2018) Universities in 2018: Riding trends to drive change Efficiencyexchange.ac.uk 27 June 2018.

Wagenaar, R. (Ed.). (2018). Tuning-CALOHEE Assessment Reference Frameworks for Civil Engineering, Teacher Education, History, Nursing, Physics. Groningen.

Wagenaar, R. (2019a). Reform! Tuning the Modernisation Process of Higher Education in Europe. A Blueprint for Student-Centred Learning. Groningen, 2019.

Wagenaar, R. (2019b). Lifelong learning for lifelong employability, Enduring learner of the (near) future. THE Europe Student Success Forum, July 2019.

Wagenaar, R. (2019c). A History of ECTS, 1989-2019. Developing a World standard for Credit Transfer and Accumulation in Higher Education. Bilbao and Groningen.

Weber, L. \& Bergan, S. (Eds.). (2005). The public responsibility for higher education and research. Council of Europe higher education series No. 2. Strasbourg: Council of Europe Publishing.

WEXHE Website https://wexhe.eu - accessed 1 November 2019.

World Bank, (2005). Country Note F. Lessons and Controversies From Financial Crises in the 1990s. In Economic Growth in the 1990s: Learning from a Decade of Reform (pp. 242-251). http://www1.worldbank.org/prem/lessons1990s/ accessed 8

Open Access This chapter is licensed under the terms of the Creative Commons Attribution 4.0 International License (http://creativecommons.org/licenses/by/4.0/), which permits use, sharing, adaptation, distribution and reproduction in any medium or format, as long as you give appropriate credit to the original author(s) and the source, provide a link to the Creative Commons license and indicate if changes were made.

The images or other third party material in this chapter are included in the chapter's Creative Commons license, unless indicated otherwise in a credit line to the material. If material is not included in the chapter's Creative Commons license and your intended use is not permitted by statutory regulation or exceeds the permitted use, you will need to obtain permission directly from the copyright holder. 